\title{
"I Need to Be the First One With a Different Approach and to Make a Difference to the People" - Transforming Pediatric Training for Non-physician Clinicians in Malawi: A Mixed-method Study
}

Farzana Yasmin ( $\square$ farzana.yasmin@uni-wh.de )

Universitat Witten/Herdecke https://orcid.org/0000-0001-6006-1997

Andreas Schultz

University of Malawi College of Medicine

Ajib Phiri

University of Malawi College of Medicine

Ralf Weigel

Universitat Witten/Herdecke

Research

Keywords: Non-physician clinician, Clinical officer, Capacity development, Health partnership, Child health, Malawi, Low-and middle-income country, Transformative learning, Interdependence in education, Change agent

Posted Date: July 2nd, 2020

DOI: https://doi.org/10.21203/rs.3.rs-38977/v1

License: (c) (i) This work is licensed under a Creative Commons Attribution 4.0 International License.

Read Full License 


\section{Abstract}

Background: Malawi has a critical shortage of skilled health workers limiting its ability to achieve its outlined national health goals. To address this, in 2012, theMinistry of Health and the College of Medicine introduced a three-year specialist Bachelor of Science (BSc) degree in Paediatric and Child Health (PCH) for Clinical Officers, a non-physician clinician cadre. In this training program, learning occurs through supervised ward rounds, bloc courses, and a research project. The German Society of Paediatrics and International Child Health, with funding from the German government, provided support between 09/2017 and $08 / 2019$. This study aims to evaluate this support project to model the training for the coming cohorts of BSc PCHCO students.

Methods:All 17 currently enrolled students took partin this study. Quantitative data was collected between 01/2018 using the Research Self-Efficacy Scale (RSES, ten-point scale), Stages of Change (SOC, fourpoint scale), and the post-self-assessment survey of bloc courses (five-point scale). In addition, three focus group discussions and five in-depth interviews with students and key informants were conductedduring April 1-10, 2019.

Results:The mean (SD) scores for RSES and SOC model were $9.10(0.91)$ and $3.54(0.40)$ respectively; for the bloc course post-self-assessment it was $3.26(0.48)$. Students found the program well-paced, felt that their clinical knowledge and skills had improved, and valued the acquired holistic approach of disease management which included the social determinants of health. They reported increased confidence and being more prepared for leadership roles at their facility and community. The involvement of international lecturers enriched their global perspectives. Students had concerns about theirrecognition in the government system and continued support after graduation. The shortage ofsupervising and teaching staff was perceived as a key barrier to continuing the program.

Conclusion: Studentsimproved theirclinical expertise, developed self-efficacy, andnew attitudes towards research. Application of various educational strategies through this project and the involvement of teachers from diverse backgrounds may enable them to build their professional networks. Continuous professional development and alumni mentoring are recommended to sustain the achieved results.

\section{Background}

The critical shortage of skilled human resources is a major drawback of Malawi's health system and a barrier to achieving health goals [1, 2].Physician and nurse/midwife ratios in Malawi are among the lowest in the world, affecting particularly the people living in rural areas [3]. Between 2006 and 2012, 80\% of recent medical graduates were retained in the public sector;however, less than one-third of them were working in rural areas [4]. Although $80 \%$ of the population lives in rural areas,only $26 \%$ of the health facilitiesare located there [5]. No pediatric specialists are available in rural hospitals[4]. Limited opportunities to network, to refer, and a feeling of professional isolation may contribute to the situation [6]. 
To address this crisis, the Malawigovernment trained clinical officers (CO), a non- physician clinician (NPC) cadre,to provide health care services, especially in rural areas[7]. These COs remain in the country's health system and may take on tasks from specialists to allow people living in rural areas access to a degree of specialized services [6]. However, inadequate living and working conditions, limited career development opportunities, low remuneration and professionalstatus combined with a lack of a staff retention strategycan pay a toll to the CO's motivation[8, 9].A strategy to counter some of these barriers might be improvingthe CO's clinical and non-clinical skills.Better skills in leadership, communication and networking with actors in- and outside of Malawi might transform their role at their workplace.

The theoretical underpinnings for this strategy are transformative learning and interdependencein education.Both lead to constructional and institutional reforms, that are central to the concept of developing "change agents"[10,11]. Both are consequences of fundamental shifts. Transformative learning is about shifting"from fact memorization tosearching, analysis, and synthesis of information fordecision making; from seeking professionalcredentials to achieving core competencies foreffective teamwork in health systems; and from noncriticaladoption of educational models to creativeadaptation of global resources to address localpriorities"[10]. Interdependence in education is about shifting "from isolated toharmonized education and health systems; from standaloneinstitutions to networks, alliances, and consortia;and from inward-looking institutional preoccupations toharnessing global flows of educational content, teachingresources, and innovations" [10].

With these theories in mind,the College of Medicine (CoM) and the Ministry of Health ( $\mathrm{MoH})$ of Malawiintroduced a three-year specialist Bachelor of Science (BSc) training program in Paediatric and ChildHealth (PCH) for COs in 2012, following successful blueprints from other specialties[4]. The German Society of Tropical Paediatrics and International Child Health (GTP) through a partnership project with the CoM, Campus Lilongwe, supported this training programfrom September 2017 to December 2019. The partnership provided intense supervision, consultation and mentoring in-country in one central and four peripheral health facilities to strengthen local services [4].

This studyaims to evaluate the part of the specialist BSc PCH CO training program that was supported by the partnership projectto provide recommendations to the forthcoming cohortsof BSc PCH CO students. The objectives are to examine if the training project contributed to (1) improving the students' clinical knowledge and skills, (2) enhancing their non-clinical skills including their attitude and approach to care, leadership role, and networking and communication skills, and (3) increasing the quality of care.

\section{Methodology}

\section{Regular and supported training modalities}

The regular three-yearBSc PCHtraining program consists of one semester (six months) of basic medical sciences, two "district semesters" of supervised placement in the district hospitals, and three semesters of supervised placement in a central hospital. During the first district semester, students learn on-the-job during as "junior clinical attachment" aboutacute pediatric care, health promotion and prevention. The 
seconddistrict semesteras "senior clinical attachment" concentrates on developing skills to lead pediatric work at the district level and master pediatric health programs.Another focus is effective collaborative networking for referral, advocacy and leadership skills [4].

The partnership project complemented the existing regular training program by strengthening service improvement, structural reinforcement and knowledge and skills improvementthrough the following training modalities: (1) supervised ward roundswith one-to-one clinical sessions at the bedside in the central and district health facilities; (2) bloc courses including different clinical and non-clinical modules with technical, mainly disease or system-specific content,or non-technical, more reflective modulesabout communication, leadership and other topics; and (3) a research project,complementing the existing theoretical part of the research module. The research project was intensely supervised through weekly consultations for planning, implementing and presenting the findings, all in the format of group work. Students designed the research, collected and analyzed their data and wrote a report.

\section{Study design and sampling frame}

For this mixed-method study, all BSc PCH students that were currently enrolled in the training program were eligible. The combination of quantitative and qualitative methods and the use of the different tools [(e.g. post-self-assessment survey of bloc courses,Research Self-Efficacy Scale(RSES), Stages of Change (SOC), in-depth interview (IDI), focus group discussion (FGD)] improved the reliability and validity of data $[12,13]$. The evaluation used process indicators to show how the bloc courses were delivered, how supervised visits were done, and how research projects were supervised. Content indicators displayed what was delivered during the teaching. Different outcome indicators demonstrated how supervised ward rounds and bloc courses helped in daily clinical practice and changed the attitude, behavior, and practice of students. Outcome indicators also informed about the completed research project/s, a change in competence, and altered confidence in research skills. These indicators measured the results of the training modalities [12, 14](Table 1).

\section{Data collection and analysis}

\section{Quantitative part}

The post-self-assessment survey of bloc courses used both Likert Scale (a five-point scale) and openended questions (additional file 1). The research skills were assessed by using Likert scales in the RSES and SOC[12, 13] (additional file 2). The RSES assesses the research self-confidence using a ten-point scale ( $1=$ not able at all, to $10=$ very able); the SOC assesses the research related changes in attitudes, intentions, and actions using a four-point scale ( $1=$ strongly disagree,to $4=$ strongly agree). All eligible students $(n=17)$ received the post-self-assessment survey questionnaire for bloc courses. Fifteen out of 17 questionnaires were returned, 10 of these were fully completed and included in the final analysis.During the study period, 13 students conducted a small-scaleresearch project and received the RSES and SOC questionnaires. Ten out of 13 students answered the RSES and SOC questionnaires, which were included in the analysis. The RSES and SOC questionnaires were applied when students had 
completed their research projects and therefore only contain post-assessment data. Data were collected between January 2018 and June 2019 and analyzed using Microsoft Excel version16.

\section{Qualitative part}

Qualitative data were collected using a semi-structured interview guide for FGD and IDI (additional file 35).All eligible students were recruited $(n=17)$ and interviewed. Three FGDs (one from each intake year) and two IDIs were conducted to capture the views from all levels of the graduate students. Three supervisors involved in the program implementation were interviewed as key informants. The study objectives were explained to each participant and written informed consent was obtainedbefore the interview (additional file 6-9). Interviews took place at KamuzuCentral Hospital (KCH) in Lilongwe, at Salima and Mchinji district hospitals, and at Queen Elizabeth Central Hospital in Blantyrebetween April 1 and 10,2019 . The "modified grounded theory" with a mix of inductive and deductive approachesand a thematic approach were used for analysis[15].

\section{Results}

\section{Quantitative part}

The overall mean (SD) rating of $3.26(0.48)$ on the five-point scale for post-self-assessment of the bloc coursesin Table 2points to the high quality of the bloc courses and the students'satisfaction. Specifically, the teaching's major effecton the students'perspective on the public health system in Malawi was rated highly. The topics of the bloc coursemodules, the teaching quality, and the impact of the bloc courses on theclinical practice were also very highly rated by the students.

The overall mean (SD) rating of 9.10 (0.91) on the 10-point scale of the RSES in Table 3shows the development of students'research self-efficacy that allowed them to conduct a small research project on their own. Studentsfelt enabled to identify and formulate research problems and questions,to perform a literature search, and to write aliterature review. They also gained the confidence to research a team, to plan, to collect data, and to present their findings.

The project also changed the students' research-related attitudes, intentions and actions in a positive way, as indicated by the respective overall mean (SD) ratings of $3.99(0.08), 3.85(0.32)$ and $2.78(0.85)$ in Table 4. They strongly agreed that learning and understanding research and incorporating it into their clinical practice is important and that they plan toincorporate research and make use of the findings in their clinical practice. For the "action" statement of the SOC model,the perceived change is smaller compared to the attitudinal and intentional statements. Being involved in another than the current research project appears to be rare.

\section{Qualitative part}

The findings are presented according to emerging themes from the open-ended post-self-assessment survey questionnaires, the IDIs and FGDs. The IDI and FGD numbers, the location of the interview and the 
date of the interview are given in brackets after the quotes.

\section{Clinical knowledge, skill, and self-confidence}

All interviewed students referred the bloc courses and supervised ward rounds as being helpful and relevant to their daily clinical practice. It helped themto improve their clinical knowledge and skills by addressing their gaps in theory and practice. It also improved their clinical reasoning and problem-solving capacity. The bloc courses also widened their knowledge in the differential diagnoses, making them more confident in patient management.

"We [supervisor and students] can discuss [case-based learning] ... come up with the diagnosis and then management...if I see the same case second time in the same condition...I will have enough knowledge to manage that" (IDI1/MJ/04042019).

"You [students] are the first one to crack [deal with] the patients... the first thing you learn from there [in wards] is that one has confidence" (FGD1/LG/02042019).

The combination of bloc courses and supervised ward rounds helped the students to assess and manage the patients, and to make the decision for a referral.

"It is very important to be equipped with the proper knowledge to make the proper diagnosis and to make the proper first management, treatment and to make the proper decision of referring on time" (FGD3/BT/08042019).

\section{Evidence-based clinical practice and quality of care}

Students stated that having research skillsisvery important as a health care professional. It helped them to deliver evidence-based care in patient management.

"Research skills are important because it has helped me to understand both scientific and ethical way how to address a relevant topic in medical profession" (RSES-SOC-6).

Studentsalso valued the importance of doing their own research to use evidence in their clinical work, linked to their own context and needs. This practice is not very common in the African context, they felt. They also believed that it would contribute to improved quality of care.

"In developing countries like Malawi, there are few clinical research projects. Most studies that influence our clinical practice is either adopted from research done outside Africa or in a few African countries. These findings might be irrelevant to our setting. Hence, it is important to enhance local research to strengthen our health system...... Research-based clinical practice will enable our system to improve care [quality] and reduce the morbidity and mortality' (RSES-SOC-9).

Though studentswere interested and valued the importance of being involved in further research, they were concerned about thelack of funding and resources to continue it at the district level. 


\section{A holistic approach to disease management}

Studentsmentioned having gained a more holistic approach todisease management during the training program. They learned to consider patients' andtheir families'socio-economic and psychological situation, acute and chronic disease, and to identify the root causes of the diseases. Students believed that their approach would help to reduce the disease burden and hospital admissions.Communication with the patients' families and counseling them are also part of the disease management mentioned by the students.

"We should not look only on the disease, but also on the other aspects... to know a patient holistically... that a child can be treated holistically in all aspects" (FGD3/BT/08042019).

"Itry to dig more and try to find the reason and to address that... to avoid that the child will not come back again with malnutrition[example of a malnourished case]" (FGD2/SL/03042019).

\section{Communication and networking capacity}

Students mentioned that the bloc course module on "Communication" together with the practices during the supervised ward rounds improved their communication skills within and outside the team and health facility. As a result, teams work more effectively, which is important in clinical practice, according to the students.

"Teamwork is the most important thing in medicine[clinical practice]. You gain a lotof clinical knowledge, but if you don't develop or grow the knowledge of teamwork, then that is nothing... we have learned here to build an effective team" (FGD3/BT/08042019).

Students valued good communication with the patients and their families for keeping them informed and involved in decisionmaking about disease management and referral. Moreover, the personal network of the students with physicians from different hospitals made them feel connected which was seen as useful for referrals. Students also connected frequently with their supervisors and other students by using technology, such as WhatsApp. Technology became a platform for the students to discuss clinical cases and helped them to diagnose, treat and refer the patients on time.

\section{Leadership skills}

Leadership was one of the non-clinical skills the project had focused on. Students mentioned that the process of learning made them feel confident, prepared them to play a leadership role, or act as a role model at their facility and community.

"We have learned a lot about leadership... different attitude... how we can approach certain problems, how we can solve certain problems, even the conflicts within the workers" (FGD3/BT/08042019).

"I need to be the first one with a different approach and to make a difference to the people" (IDI1/MJ/04042019). 


\section{The global context of teaching and learning}

Students valued the involvement of international teachersand supervisors as it put their knowledge and work into a global contextand widened their horizons.

"It is not only one country that it becomes the whole world coming together...It is like teaching us and making us fit for everything as far as the globe is concerned" (FGD1/LG/02042019).

Students appreciated reading the latest scientific articles during the bloc courses which put their knowledge in an international context. As a result, they became familiar with global standards and guidelines of health care. This exposure helped them to better understand how global decisions influence local practice and how different countries put different emphasis on health topics.

\section{Motivation}

Obtaining new knowledge, serving the children with this knowledge, improving the overall health situation of the country, and advancing their career motivated the students.

"... a lot of children are suffering and dying there [at district]because of mistreatment and mismanagement ... when I go back home [at district], I should treat the patients even with the least management that is there [available at district level]. But, I have to give the best management"(FGD1/LG/02042019).

Through the new knowledge and skills acquired in research, students became more autonomous and motivated to improve the quality of care at their facilities.

"I will be the pediatric team lead in the district, it is paramount for me to do research by myself to improve the quality of care in the pediatric department" (RSES-SOC-7).

\section{Students concerns beyond the learning modalities}

Studentsexpressed their concern ifthe new cadre (specialist pediatric $\mathrm{CO}$ ) will be acknowledged in the government system bya salary raise. Otherwise,they saw the risk of this cadre leaving the public sector.

"If they [COs] are not promoted [with a new title and pay scale], they will go out [of the government system] and the gap will remain the same"(FGD3/BT/08042019).

Students were worried abouttheir further professional developmentand about having the opportunity to do a Master's degree in the relevant field. A Master's degree was seen as a motivation for them as well as for the upcoming COs. They suggested continuing the supervisionsupport after their graduation and recommended to continue thetraining program with more students. They felt this to be a requirement to deal with the shortage of health care workers at the district level and to improve the quality of care.Thekey informants agreed with the students' views, but mentioned the shortage of supervising and 
teaching staff as an additional barrier.Several logistical issues, for example, lack of financial support, high tuition fees, and lack of an accommodation facility during their study were mentioned.

\section{Discussion}

The BSc PCH CO students in this evaluation were highly satisfied with the training modalities delivered with the support of this educational partnership project. Their scores indicate a perception of better clinical and non-clinical skills as well as an improved attitude towards practice-related research and confidence to conduct it. Students reflected on the value of a professional network in and outside Malawi, the need for a holistic approach to the disease management, and their ability to initiate and to receive referrals. They appreciated developing skills in communication with patients, their families and providers, networking and leadership. They felt prepared to exercise evidence-based clinical practice through the gained research skills.

The findings illustrate how a North-South educational partnership project can succeed in providing innovative aspects to an existing curriculum for a specialized NPC cadre through the delivery of a transformative learning experience and development of interdependence in education. The combined classroom and practical case-based teaching at the bedside enhanced the students' clinical reasoning and problem-solving. It developed their evidence-based decision-making in diagnosing, treating and referring pediatric patients. These capabilities are cornerstones of quality services[16]. Deeper insights about the role of the social determinants of health, adding global perspectives, may allow viewing patients more holistically, beyond purely managing their diseases[10,17]. The transformation we assume has occurred could cause the changes in attitude, behavior, and practice needed to provide better quality care.

Students developed research skills that helped them to connect evidence and practice, reflecting a fundamental shift that is associated with transformative learning and a motivation to work. The daily routine of heavy clinical workmakes it hard for COs to find time and energy to update their knowledge and skills for changing practice and this might negatively affect their motivation. To counteract this development, the program included a research module complemented by a supervised research project. This evaluation showed that BSc PCH students' improved searching, analyzing, and synthesizing capacities.Applying these capacities,studentsself-selected and conductedtheir research, led by local needs, and aligned with national agendas. As their independent research projects were embedded in the political and cultural context,the uptake of their findings by practitioners and policymakers is more likely [18]. Working based on self-researched evidence and witnessing it being used must be motivating. Indeed, studiesshowedthat strengthening research capacities is the most powerful and sustainable means of advancing health care [18].

The improved communication and networking skills and experiences observed may represent changes resulting from ashift fromisolated and standalone to a more harmonized and connected educational model- a hallmark of interdependence in education.A specificallydesigned bloc course module titled 
"Communication" aimed to improve students' communication with patients and their families, and with colleagues in and outside the team and the facilities. In addition, students and teachers introduced WhatsApp for clinical case-based discussions and referral decisions.Communication skills, including the use of technology, arecritical for a good working relationship, engagement of the clinical team,and patient-centered, timely, and safe services [19]. Moreover, this training project involved teachers and students from diverse backgrounds giving the communication a strong international perspective by using international educational and research materials. Students felt connected, expanded their worldview, and acquired competences to adapt global resources to address their local priorities[20, 21].

Ensuring that achieved results are maintained is a common challenge in partnershipprojects[18]. Will the project have lasting effects on students and local institutions? First, this partnership projecthad built on an existing BSc PCH training program, developed through local resources, implemented by local staff, and addressing local needs.It expanded and complemented through careful analysis of the existing training program by shared decision-making ensuring national ownership, and in an atmosphere of mutual trust[22, 23]. Second,the project was designed to improve students' autonomy and to enablelocal partners to determine their needs and priorities-pre-requisites for local ownership and sustainability[18, $22,24]$. Third, Malawi's MoH has officially recognized the graduates as "Clinical Associates" and considers increasing their salaries. Adequate recognition, remuneration, working conditions, and a career path are essential to retaining graduates in the public serviceand this also plays a part in maintaining the achievements of this project [11]. However, funding of the training program itself is also important and if lacking may become a major threat for the BSc PCH CO training scale-up [24].

There are other risks too. If the skills and motivation of graduates are to be maintained, they need support in the future. The shortage of health workers and the limited availability of a dedicated teaching faculty for NPC training in the government system are challenges [9]. Ongoing supervision and mentoringof the $\mathrm{BSc} \mathrm{PCH}$ COs through $\mathrm{MoH}$ structures and employees as well as a strengthened system of continuous professionaldevelopment (CPD) are needed, according to this study. An e-learning platform using a network of national and international resources, as suggested by WHO, might be an opportunity[11]. Ongoing support through CPD and mentoring will help to keep the students motivated and overcoming professional isolation. Similarly, funding to allow continued linkage with the international research and teaching community is needed[24]. Students' improved communication and networking skills can also help with mobilizing international grants opportunities for further research[22].

\section{Strengths and limitations}

The inclusion of all current students allowing an analysisof the full sample is a strength of the study. In addition, the study used methodological (mixed methods), data (RSES, SOC, survey, interviews) and investigator triangulation (FY, AS, RW) to validate its findings. Limitations are 1) absence of a control group to be examined in parallel or a pre-and-post comparison, 2) difficulties to define the exact contribution of the partnership project as it complements an existing $\mathrm{MoH}$ program, and 3) the cross- 
sectional design of the evaluation of this short term, two-year project which will fall short of information about its sustainability.

\section{Conclusion}

Health professionals need attributes beyond expert clinical knowledge and skills to meet the needs of 21 st-century health system challenges $[10,11]$. This is to serve their patients better, but also to withstand lack of motivation through exhausting working conditions. The training modalities added to the existing curriculum for $\mathrm{BCs} \mathrm{PCH}$ CO students through this partnership aimed at creating a transformative learning experience and interdependence in education. Thisevaluation shows major achievements in that direction, laying the foundation for this cadre to enact change at their workplace and serve as a role model for a more comprehensive approach to child care in low resource settings. To sustain these achievements and to realize the potential of this new cadre, we recommend adopting the additions as a regular part of the BSc PCH curriculum. Alumni of the BSc PCH training would benefit from CPD initiatives and mentoring. Monitoring and evaluation of the cadre's actions and the realities at their workplaces would be helpful to assess the long-term effects of the training.

\section{Declaration}

- Ethical approval: The study got the ethical approval from the Ethics Commission of the Witten/HerdeckeUniversity, Germany (AntragNr. 94/2018), and the College of Medicine, Malawi (P.06/18/2428) (Additional files 10 \& 11).

- Consent for publication:Not applicable.

- Availability of data and materials: Data will be available on request. The first (FY) author is responsible for data access.

- Competing interest:All authors declare no competing interests.

- Funding:The project and the study were funded by the Federal Ministry for Economic Cooperation and Development (BMZ), the Else Kröner-Fresenius-Stiftung (EKFS), the German Society of Paediatrics and International Child Health (GTP), and the Friede Springer Endowed Professorship for Global Child Health, Witten/Herdecke University, Germany.The funding bodies played no role in the design of the study and in the collection, analysis, and interpretation of data and in writing the manuscript.

- Authors' contributions:FY and AS are sharing the first authorship of this study. Design of the study: FY, AS, AP, RW; Quantitative data collection: AS; Conduction of qualitative interviews: FY; Data entry and analysis: FY; Data Triangulation: FY, AS, RW; Drafting of the manuscript: FY, AS and RW;Program implementation: AS and AP.All authors have read and approved the manuscript. FY and AS are guarantors of the paper. 
- Acknowledgments:We are grateful to the graduates of the BSc PCH CO program of the College of Medicine, Malawi for their contribution to the study.

\section{- Author's information:}

Farzana Yasmin: Research Associate, Friede Springer Endowed Professorship for Global Child Health, Witten/HerdeckeUniversity, Alfred-Herrhausen-Str. 50, 58448 Witten, Germany. E-mail: farzana.yasmin@uni-wh.de

Andreas Schultz:Senior Lecturer, Paediatrics and Child Health, College of Medicine, Department of Pediatrics, University of Malawi, P.O. 30055, Lilongwe, Malawi. E-mail: andreas.schultz@rocketmail.com

Ajib Phiri:Senior Lecturer, Paediatrics and Child Health, College of Medicine, Department of Pediatrics, University of Malawi, P.O. 30055, Lilongwe, Malawi. E-mail: phiria@medcol.mw

Ralf Weigel: Professor, Friede Springer Endowed Professorship for Global Child Health, Witten/HerdeckeUniversity, Alfred-Herrhausen-Str. 50, 58448Witten, Germany. E-Mail: ralf.weigel@uniwh.de

\section{List Of Abbreviation}

BSc Bachelor of Science

BT Blantyre

CoM College of Medicine

CO Clinical Officer

CPD Continuous Professional Development

FGD Focus Group Discussion

GTP German Society of Paediatrics and International Child Health

IDI In-depth Interview

$\mathrm{KCH}$ Kamuzu Central Hospital

LG Lilongwe

MJ Mchinji

$\mathrm{MoH} \quad$ Ministry of Health

NPC Non-physician Clinician 
$\mathrm{PCH} \quad$ Paediatrics and Child Health

RSES Research Self-Efficacy Scale

SD Standard Deviation

SL Salima

SOC Stages of Change

\section{References}

1. MoH: Malawi National Health Accounts Report for fiscal years 2012/13, 2013/14 and 2014/15. In. Edited by $(\mathrm{MoH}) \mathrm{MoH}$. Lilongwe, Malawi: Ministry of Health, Department of Planning and Policy Development, Government of the Republic of Malawi; 2016.

2. Mueller DH, Lungu, D., Acharya, A., Palmer, N.: Constraints to implementing the Essential Health Package in Malawi. PLoS One 2011, 6(6):e20741.

3. UNICEF: 2016/17 Health Budget Brief. In. Edited by Malawi U. UNICEF House, Lilongwe, Malawi; 2017.

4. O'Hare B, Phiri, A., Lang, H. J., Friesen, H., Kennedy, N., Kawaza, K., Jana, C. E., Chirambo, G., Mulwafu, W., Heikens, G. T., Mipando, M.: Task sharing within a managed clinical network to improve child health in Malawi. Hum Resour Health 2015, 13:60.

5. MoH: Health Sector Strategic Plan II 2017-2022. Towards Universal Health Coverage. . In. Edited by $(\mathrm{MoH}) \mathrm{MoH}$. Ministry of Health, Lilongwe 3, Malawi: Ministry of Health $(\mathrm{MoH})$, Government of the Republic of Malawi; 2017.

6. Ellard DR, Shemdoe, A., Mazuguni, F., Mbaruku, G., Davies, D., Kihaile, P., Pemba, S., Bergstrom, S., Nyamtema, A., Mohamed, H. M., O'Hare, J. P.: Can training non-physician clinicians/associate clinicians (NPCs/ACs) in emergency obstetric, neonatal care and clinical leadership make a difference to practice and help towards reductions in maternal and neonatal mortality in rural Tanzania? The ETATMBA project. BMJ Open 2016, 6(2):e008999.

7. Mullan F, Frehywot, S.: Non-physician clinicians in 47 sub-Saharan African countries. Lancet 2007, 370(9605):2158-2163.

8. Gajewski J, Mweemba, C., Cheelo, M., McCauley, T., Kachimba, J., Borgstein, E., Bijlmakers, L., Brugha, R.: Non-physician clinicians in rural Africa: lessons from the Medical Licentiate programme in Zambia. Hum Resour Health 2017, 15(1):53.

9. Eyal N, Cancedda, C., Kyamanywa, P., Hurst, S. A.: Non-physician Clinicians in Sub-Saharan Africa and the Evolving Role of Physicians. Int J Health Policy Manag 2015, 5(3):149-153. 
10. Frenk J, Chen, L., Bhutta, Z. A. Cohen, J., Crisp, N., Evans, T., Fineberg, H., Garcia, P., Ke, Y., Kelley, P., Kistnasamy, B., Meleis, A., Naylor, D., Pablos-Mendez, A., Reddy, S., Scrimshaw, S., Sepulveda, J., Serwadda, D., Zurayk, H.: Health professionals for a new century: transforming education to strengthen health systems in an interdependent world. Lancet 2010, 376(9756):1923-1958.

11. WHO: Transforming and scaling up health professionals' education and training: World Health Organization Guidelines 2013. In. Switzerland: WHO; 2013.

12. Bates I, Ansong D, Bedu-Addo G, Agbenyega T, Akoto AY, Nsiah-Asare A, Karikari P: Evaluation of a learner-designed course for teaching health research skills in Ghana. BMC Med Educ 2007, 7:18.

13. Buckley LL, Goering, P., Parikh, S.V., Butterill, D., Foo, E.K.H.: Applying a 'stages of change' model to enhance a traditional evaluation of a research transfer course. Evaluation in Clinical Practice 2003, 9(4):385-390.

14. Cervero R: Continuing professional education and behavioural change. J Contin Educ Nurs 1985, 16:85-88.

15. Pope C, Mays, N.: Qualitative research in health care. In. Edited by books B. Massachusetts, USA: Blackwell publishing; 2006.

16. McLean SF: Case-Based Learning and its Application in Medical and Health-Care Fields: A Review of Worldwide Literature. J Med Educ Curric Dev 2016, 3.

17. Victorino CC, Gauthier, A. H.: The social determinants of child health: variations across health outcomes - a population-based cross-sectional analysis. BMC Pediatr 2009, 9:53.

18. Franzen SR, Chandler, C., Lang, T.: Health research capacity development in low and middle income countries: reality or hetoric? A systematic meta-narrative review of the qualitative literature. BMJ Open 2017, 7(1):e012332.

19. Merlino J: Patient safety \& quality healthcare. In: Communication: A Critical Healthcare Competency 2017.

20. Hoggan C: Transformative Learning as a Metatheory: Definition, Criteria, and Typology Adult Education Quarterly 2016, 66(1):57-75.

21. Van Schalkwyk SC, Hafler, J., Brewer, T. F., Maley, M. A., Margolis, C., McNamee, L., Meyer, I., Peluso, M. J., Schmutz, A. M., Spak, J. M., Davies, D., Bellagio Global Health Education, Initiative:

Transformative learning as pedagogy for the health professions: a scoping review. Med Educ 2019, 53(6):547-558.

22. Chandiwana S, Ornbjerg, N.: Review of North-South and South-South cooperation and conditions necessary to sustain research capability in developing countries. J Health Popul Nutr 2003, 21(3):288-297.

23. Eckerle M, Crouse, H. L., Chiume, M., Phiri, A., Kazembe, P. N., Friesen, H., Mvalo, T., Rus, M. C., Fitzgerald, E. F., McKenney, A., Hoffman, I. F., Coe, M., Mkandawire, B. M., Schubert, C.: Building Sustainable Partnerships to Strengthen Pediatric Capacity at a Government Hospital in Malawi. Front Public Health 2017, 5:183. 
24. Vallejo BW, U.: Capacity Development Evaluation: The Challenge of the Results Agenda and Measuring Return on Investment in the Global South. World Development 2016, 79:1-13.

\section{Tables}

Table 1:

Evaluation Framework of the study

\begin{tabular}{|c|c|c|c|}
\hline $\begin{array}{l}\text { Areas of } \\
\text { improvement }\end{array}$ & Training modalities & Sampling Frame & Tools \\
\hline \multirow[t]{2}{*}{ Services } & $\begin{array}{l}\text { Supervised ward } \\
\text { rounds }\end{array}$ & $\begin{array}{l}\text { Intake year } \\
2016 / 17\end{array}$ & IDI, FGD \\
\hline & & (8 students) & \\
\hline \multirow[t]{2}{*}{$\begin{array}{l}\text { Structural } \\
\text { reinforcement }\end{array}$} & A research project & $\begin{array}{l}\text { Intake year } \\
2017 / 18\end{array}$ & RSES, SOC, IDI, FGD \\
\hline & & (5 students) & \\
\hline \multirow[t]{2}{*}{$\begin{array}{l}\text { Knowledge and } \\
\text { skills }\end{array}$} & Bloc courses & $\begin{array}{l}\text { Intake year } \\
2018 / 19\end{array}$ & $\begin{array}{l}\text { Post self-assessment survey, } \\
\text { IDI, FGD }\end{array}$ \\
\hline & & (4 students) & \\
\hline
\end{tabular}


Table 2:

Post self-assessment survey of the bloc courses by the students $(n=10)$

\section{Questions and level of scoring (Five-point scale)}

Rate the level of the sessions

Were the topics discussed in the bloc important or relevant to your daily clinical work?

Rate the way the topic was taught (quality)

Did the bloc change the way you manage patients with conditions discussed during the module?

The course improved the way I cope with the stress of my rotation

Did the course have an effect onyour perspective on the public health system in Malawi?

The course improved my way of working with other trainees on the ward 
Table 3:

Mean score for each statement on the Research Self-Efficacy Scale (RSES) $(n=10)$

Statement (score 1-10)

As a result of the program I am able to ...

Mean

(SD)

Identify a clinical problem that is amenable to research

9.70

(0.46)

Formulate a clear research question or a testable hypothesis to address a clinical/public

9.20

health problem

Do an effective electronic database search of the literature

Write a balanced and comprehensive literature review

Choose a research design that will answer my research question or hypothesis

Put together a team to help you to conduct your research

Design and implement the best strategy for collecting my data

Design and implement the best data analysis strategy for my research study

Effectively present my study and its implications to large groups of clinical/public health

Teach someone else how to design and implement a simple research project

Write a scientific report out of my results research 
Table 4: Mean scores for statements about research related attitudes, intentions and actions - on the 'Stages of Change' (SOC) model $(n=10)$

\section{Statements for 'Stages of Change' model (Four-point scale)}

\section{Attitudes}

Learning research skills is important

Understanding how to do research is relevant to my work

I should incorporate research findings into my clinical practice

I should do more research myself

Mean (SD) of Attitudes =

Intentions

I plan to learn more about how to do research

I will bring up the idea of incorporating research into our work with colleagues

I plan to include the use of research findings in my clinical practice

I will suggest that we discuss how to improve our use of research results at our departmental meetings

Mean (SD) of Intentions =

\section{Actions}

I have suggested casually to some of my colleagues that they should do research

I have spoken in a formal meeting about increasing the amount of research done by our department

I have spoken in a formal meeting (or to my Head of Department) about increasing the use 


\section{Supplementary Files}

This is a list of supplementary files associated with this preprint. Click to download.

- Additioanlfile11EthicalapprovalMalawi.pdf

- Additionalfile10EthicalapprovalUWH.pdf

- Additionalfile9ConsentDeclerationFGD.pdf

- Additionalfile8ConsentDeclarationIDI.pdf

- Additionalfile7InformationsheetFGD.pdf

- Additionalfile6InformationsheetIDI.pdf

- Additionalfile5FGD protocolStudents.pdf

- Additionalfile4IndepthinterviewprotocolKII.pdf

- Additionalfile3IndepthinterviewprotocolStudents.pdf

- Additionalfile2LikertScaleRSES.pdf

- Additionalfile1Bloccourseevaluation.pdf 